\title{
Molecular, Structural, and Functional Characterization of Alzheimer's Disease: Evidence for a Relationship between Default Activity, Amyloid, and Memory
}

\author{
Randy L. Buckner, ${ }^{1,2,3,4,5}$ Abraham Z. Snyder, ${ }^{3,6}$ Benjamin J. Shannon, ${ }^{5}$ Gina LaRossa, ${ }^{3}$ Rimmon Sachs, ${ }^{3}$ \\ Anthony F. Fotenos, ${ }^{5}$ Yvette I. Sheline, ${ }^{3,7}$ William E. Klunk, ${ }^{9}$ Chester A. Mathis, ${ }^{9}$ John C. Morris, ${ }^{6,8}$ and Mark A. Mintun ${ }^{3}$ \\ ${ }^{1}$ Howard Hughes Medical Institute, ${ }^{2}$ Department of Psychology, ${ }^{3}$ Mallinckrodt Institute of Radiology, ${ }^{4}$ Department of Anatomy and Neurobiology, \\ ${ }^{5}$ Division of Biology and Biomedical Sciences, and Departments of ${ }^{6}$ Neurology, ${ }^{7}$ Psychiatry, and ${ }^{8}$ Pathology and Immunology, Washington University \\ School of Medicine, St. Louis, Missouri 63105, and ${ }^{9}$ Department of Neurology, University of Pittsburgh and Western Psychiatric Institute and Clinic, \\ Pittsburgh, Pennsylvania 15312
}

\begin{abstract}
Alzheimer's disease (AD) and antecedent factors associated with AD were explored using amyloid imaging and unbiased measures of longitudinal atrophy in combination with reanalysis of previous metabolic and functional studies. In total, data from 764 participants were compared across five in vivo imaging methods. Convergence of effects was seen in posterior cortical regions, including posterior cingulate, retrosplenial, and lateral parietal cortex. These regions were active in default states in young adults and also showed amyloid deposition in older adults with $\mathrm{AD}$. At early stages of $\mathrm{AD}$ progression, prominent atrophy and metabolic abnormalities emerged in these posterior cortical regions; atrophy in medial temporal regions was also observed. Event-related functional magnetic resonance imaging studies further revealed that these cortical regions are active during successful memory retrieval in young adults. One possibility is that lifetime cerebral metabolism associated with regionally specific default activity predisposes cortical regions to AD-related changes, including amyloid deposition, metabolic disruption, and atrophy. These cortical regions may be part of a network with the medial temporal lobe whose disruption contributes to memory impairment.
\end{abstract}

Key words: amyloid; PIB; memory; MCI; parietal cortex; FDG-PET; fMRI; human; prefrontal cortex; hippocampus

\section{Introduction}

Alzheimer's disease (AD) is the most prevalent dementing disorder in older adults. AD is pathologically defined by the presence of amyloid (A $\beta$ ) aggregations (plaques) and tau pathology (neurofibrillary tangles) (Khachaturian, 1985; Mirra et al., 1991; National Institute on Aging, 1997). Histological studies suggest that tau pathology is prominent in the medial temporal lobe (MTL) early in the disease and progresses outward; amyloid has a broader cortical distribution that includes but is not especially prominent in MTL (Braak and Braak, 1991, 1997; Price et al., 1991). Profound cell loss is also observed in the hippocampal formation (Hyman et al., 1984; Price et al., 1991; Gómez-Isla et al., 1996). Consistent with this pathology, in vivo magnetic resonance imaging (MRI) structural measures in early-stage $\mathrm{AD}$

Received May 29, 2005; revised July 11, 2005; accepted July 11, 2005

This work was supported by National Institute on Aging Grants P50 AG05681 and P01 AG03991, the Mallinckrodt Institute of Radiology, the Alzheimer's Association, the James S. McDonnell Foundation, and the Howard Hughes Medical Institute. We thank the Washington University Alzheimer's Disease Research Center, including Mary Coats, Amy Buckley, Elizabeth Grant, and Martha Storandt. Marcus Raichle and David Holtzman provided valuable discussion. Robert Mach, Carmen Dence, and Song Yoon Lee synthesized [ $\left.{ }^{11} \mathrm{C}\right] \mathrm{PIB}$ and its precursor. David Van Essen provided Caret software, and Karl Herholz generously provided FDG-PET data.

Correspondence should be addressed to Dr. Randy L. Buckner, Howard Hughes Medical Institute at Washington University, Campus Box 1125, One Brookings Drive, St. Louis, M0 63105. E-mail: rbuckner@artsci.wustl.edu. DOI:10.1523/JNEUROSCI.2177-05.2005

Copyright $\odot 2005$ Society for Neuroscience $\quad$ 0270-6474/05/257709-09\$15.00/0 demonstrate medial temporal atrophy (for review, see Jack and Petersen, 2000).

Given the coexistence of pathology and atrophy in the MTL, it is puzzling that $\left[{ }^{18} \mathrm{~F}\right]$-2-fluoro-2-deoxy-D-glucose positron emission tomography (FDG-PET)-measured hypometabolism is most prominent in temporoparietal and retrosplenial association cortex (Friedland et al., 1983; Herholz, 1995; Reiman et al., 1996). Nondemented individuals, genetically at risk for late-onset AD, also show these metabolic differences (Reiman et al., 1996). An open question is how patterns of metabolic disruption relate to structural atrophy and underlying neuropathology. One possibility is that metabolic effects in posterior cortical regions represent the secondary consequences of MTL pathology. Posterior cortical regions are densely interconnected with the MTL (Insausti et al., 1987; Vogt et al., 1992; Suzuki and Amaral, 1994; Meguro et al., 1999; Morris et al., 1999; Kobayashi and Amaral, 2003). Another possibility is that these cortical regions are directly affected by pathology resulting in atrophy early in the disease (Buckner, 2004). Here we revisit this issue using anatomic procedures sensitive to longitudinal cortical atrophy (Fox et al., 2001) in patients with early-stage $\mathrm{AD}$ and individuals at the cusp of clinically expressed $\mathrm{AD}$, in conjunction with mapping amyloid deposition using the recently developed amyloid-imaging tracer $\left[{ }^{11} \mathrm{C}\right]$ Pittsburgh Compound-B (PIB) (Klunk et al., 2004). To foreshadow the results, there is correlation in posterior cortical regions be- 
Table 1. Data types integrated in the present study

\begin{tabular}{ll}
\hline Default activity, $\mathrm{H}_{2}$ O-PET & $\begin{array}{c}\text { Updated meta-analysis of nine published PET } \\
\text { studies [data from Shulman et al. (1997b)] }\end{array}$ \\
$\begin{array}{l}\text { Amyloid deposition, PIB-PET } \\
\text { Structural atrophy, MRI }\end{array}$ & New data \\
Glucose metabolism, FDG-PET & Multicenter data from Herholz et al. (2002) \\
Retrieval success effect, fMRI & Meta-analysis of data \\
\hline
\end{tabular}

tween amyloid deposition, atrophy, and hypometabolism, suggesting a network that is directly disrupted in early-stage AD.

The present analyses also explore early life risk factors for AD based on the study of default mode activity in young adults. Although PET and functional MRI (fMRI) imaging most often seek to identify areas of increased activity related to specific active tasks (e.g., speaking, classifying a stimulus, etc.), many published functional imaging studies note regions that are more active during rest or in the passive control condition compared with the active task condition (Shulman et al., 1997b; Mazoyer et al., 2001; McKiernan et al., 2003). The consistency of this observation has led to the hypothesis of a "default" mode of human cognition (Gusnard and Raichle, 2001). Here we demonstrate a remarkable correlation between default activity patterns in cortical regions in young adults and the topography of amyloid deposition in elderly $\mathrm{AD}$ patients. This correspondence raises the possibility of a relationship between activity patterns in early adulthood and later amyloid deposition. Of additional interest, the default activity pattern also correlates with posterior networks involved in memory retrieval, suggesting that memory may be affected prominently in $\mathrm{AD}$ because memory systems are modulated as part of default cognitive modes.

\section{Materials and Methods}

Overview. Five imaging methods were compared (Table 1). We obtained the best available estimate for each data type and then integrated them into a common anatomic space for direct comparison. Methods used to obtain the novel data are described most extensively (maps of amyloid deposition and atrophy). Analyses based on previously reported data are given in less detail (maps of default mode activity, metabolism, and the retrieval success effect). All data are averaged in a common atlas space (Talairach and Tournoux, 1988) using procedures developed to allow comparisons across the adult age span (Buckner et al., 2004). Surface representations of atlas space data were prepared using Caret software (Van Essen et al., 2001).

$\left[{ }^{15} \mathrm{O}\right] \mathrm{H}_{2} \mathrm{O}$ PET maps of default mode activity. Most published functional imaging studies that include "passive" control conditions (e.g., passive viewing and rest) note regions more active in the control condition compared with the active task condition. These responses are sometimes referred to as task-induced activity decreases or default mode activity because of their consistent appearance across numerous passive task conditions. Shulman et al. (1997a,b) conducted a formal metaanalysis of regions active during passive control conditions compared with task performance spanning verbal and nonverbal domains. All participants were normal, right-handed young adults (ages were 18-41 years). The grand average difference image in Shulman et al. (1997b) included 426 scan pairs acquired in 132 individuals over nine studies. This grand average was recomputed here using updated methods (Burton et al., 1999), including correction for interscan head movement and atlas transformation by 12-parameter affine warp to an atlasrepresentative average $(n=12)\left[{ }^{15} \mathrm{O}\right] \mathrm{H}_{2} \mathrm{O}$ PET target image. The $\left[{ }^{15} \mathrm{O}\right] \mathrm{H}_{2} \mathrm{O}$ PET target image was prepared using methods similar to those used to create corresponding MRI and PET primate atlas representative images (Black et al., 2001a,b). This image maps regions more active at rest or in a passive control condition (i.e., in the default mode) relative to goal-directed task performance.

$\left[{ }^{11} C\right]$ PIB-PET maps of amyloid deposition. Radiotracers with high affinity of amyloid (in $\mathrm{A} \beta$ plaques) have been developed recently for use in
Table 2. PIB amyloid imaging sample

\begin{tabular}{lcc}
\hline & Nondemented & AD \\
\hline$n$ & 8 & 10 \\
Male/female & $5 / 3$ & $7 / 3$ \\
Age (years) & 76.8 & 75.2 \\
Education (years) & 16.4 & 13.4 \\
CDR $(n)$ & $0(8)$ & $0.5(7), 1(3)$ \\
MMSE & 29.0 & 25.0 \\
\hline
\end{tabular}

CDR 0 , No dementia; CDR 0.5, 1, and 2, very mild, mild, and moderate dementia, respectively. Numbers in parentheses within CDR rows indicate the number of participants with each CDR.

humans (Kung et al., 2002; Shoghi-Jadid et al., 2002; Mathis et al., 2003). Here we used [ ${ }^{11}$ C]PIB (Klunk et al., 2001; Mathis et al., 2002; Klunk et al., 2004) to image amyloid in a sample of $\mathrm{AD}$ participants and agematched controls. These images map regions of amyloid deposition.

Participants. Eighteen older participants were enrolled from the longitudinal sample of the Washington University Alzheimer's Disease Research Center and screened to exclude neurological illness, psychoactive medications, and medical conditions that might produce cognitive impairment. The presence or absence of dementia and, when present, its severity was classified based on the Clinical Dementia Rating (CDR) (Morris, 1993). Eight participants were nondemented, and 10 were very mild to mildly demented with $\mathrm{AD}$. The clinical diagnosis of $\mathrm{AD}$ in our sample, even in its very mildest stages, has been validated by neuropathological examination (Berg et al., 1998; Morris et al., 2001). All participants consented in accordance with the Washington University Human Studies Committee guidelines. Table 2 presents sample characteristics.

Imaging methods. Images of amyloid deposition were acquired on a 961 ECAT PET scanner (Siemens, Erlangen, Germany) while participants rested with eyes closed. A catheter was placed in the antecubital vein. Head position was such that the cantho-meatal line was $\sim 1.0 \mathrm{~cm}$ above, and parallel to, the lowest imaging plane. A transmission scan was obtained to correct for attenuation. Imaging used $8-18 \mathrm{mCi}$ of $\left[{ }^{11} \mathrm{C}\right] \mathrm{PIB}$ and a 60 min dynamic PET scan in three-dimensional (3-D) mode (septa retracted, $24 \times 5$ s frames; $9 \times 20 \mathrm{~s}$ frames; $10 \times 1$ min frames; $9 \times 5$ min frames). All participants were separately imaged using MRI (see below).

The dynamic PET images were reconstructed with scatter correction using the commercially provided routines for 3-D PET data and a ramp filter (resolution of $\sim 5.5-6 \mathrm{~mm}$ full-width half maximum; after 3-D Gaussian filter, final resolution of $\sim 8.5 \mathrm{~mm}$ ). PET-MR alignment was performed using cross-modal registration maximizing alignment of intensity gradients taking into account relative gradient orientation (Pluim et al., 2000). Head motion was corrected using the cross-modal alignment to accommodate the dramatic changes in tissue activity distribution over the scan. Atlas registration was accomplished via each individual's structural MRI (Buckner et al., 2004). The $\left[{ }^{11} \mathrm{C}\right] \mathrm{PIB}$ atlas transformation was computed by composition of affine transforms (PET to MRI to atlas target), and data were resampled to $1 \mathrm{~mm}^{3}$ isotropic voxels in atlas space. The PET data from 30-60 min after injection were integrated to create a single image that was then normalized by regional brainstem uptake.

MRI maps of structural atrophy. Structural atrophy predicts conversion from early to late stages of AD (Fox et al., 1999; Killiany et al., 2002; Jack et al., 2004). Here maps of regional volume change were computed using fluid registration from a baseline image to a longitudinally acquired image (Fox et al., 2001; Scahill et al., 2002). Contracting voxels represent atrophy (e.g., as seen in the hippocampal formation), and expanding voxels represent dilation (e.g., as seen in ventricles). For simplicity, we plot only contracting voxels. These images map regions of atrophy as measured by longitudinal structural MRI.

Participants. Ninety-two older participants were enrolled. Inclusion criteria and dementia staging are the same as described above. Participants were divided into three groups: NONDEMENTED (CDR 0 at baseline and follow-up; $n=44)$, DEMENTED with very-mild/mild AD (CDR 0.5/ 1 at baseline and follow-up; $n=40$ ), and CONVERTER (CDR 0 at baseline with CDR $>0$ at follow-up; $n=8$ ). Table 3 presents sample characteristics. Attrition and selection characteristics of this MR sample have been described previously (Fotenos et al., 2005). 
Table 3. Longitudinal atrophy sample

\begin{tabular}{lccc}
\hline & Nondemented & Converter & AD \\
\hline$n$ & 44 & 8 & 40 \\
Male/female & $34 / 10$ & $3 / 5$ & $16 / 24$ \\
Age (years) & 78.4 & 77.7 & 76.7 \\
Education (years) & 14.9 & 15.1 & 13.5 \\
CDR time 1 ( $n)$ & $0(44)$ & $0(8)$ & $0.5(31), 1(9)$ \\
CDR time 2 $(n)$ & $0(44)$ & $0.5(8)$ & $0.5(23), 1(16), 2$ (1) \\
MMSE time 1 & 29.3 & 28.8 & 24.4 \\
MMSE time 2 & 29.1 & 28.6 & 23.9 \\
Delay (years) & 2.15 & 2.57 & 1.72
\end{tabular}

Analyses subdividing the AD participants by dementia severity do so using the CDR at time 1, yielding 31 very mild and 9 mild participants (see Fig. 3).

Imaging methods. Multiple (three or four) high-resolution structural T1-weighted magnetization-prepared rapid gradient echo (MP-RAGE) images were acquired on a 1.5-T Vision scanner (Siemens). Repetition time was $9.7 \mathrm{~ms}$, echo time was $4 \mathrm{~ms}$, flip angle was $10^{\circ}$, inversion time was $20 \mathrm{~ms}$, and resolution was $1 \times 1 \times 1.25 \mathrm{~mm}$. Fluid warp techniques (Christensen et al., 1996; Miller, 2004) were used to generate volumetric measures of contraction/expansion over time (methods similar to Fox et al., 2001; Scahill et al., 2002). The fluid warp procedure was applied after correction for movement, transformation to atlas coordinates, and resampling (Buckner et al., 2004). The serially acquired native space data were registered to the initial session data (also in native space) using a nine-parameter affine transform (rigid body translation plus rotation plus cardinal axis stretch) (Freeborough et al., 1996). The cross-session transform was algebraically composed with movement correction transforms for the second session and the first session atlas transform (12parameter affine) to generate second session atlas transforms for each MP-RAGE image. Correction for gain field inhomogeneity is embedded in our implementation of the fluid warp (supplemental data, available at www.jneurosci.org as supplemental material). A brain mask (Buckner et al., 2004) was supplied to the fluid warp procedure to prevent misregistration of extracranial structures from affecting the atrophy computations. Details of our fluid warp procedure as well as tests of reliability are given as supplemental data and supplemental Figure 2 (available at www. jneurosci.org as supplemental material). The measure of interval shape change generated by the fluid warp procedure is the displacement field, $\mathbf{u}$, which represents the intersession deformation at each voxel. We evaluated local contraction/expansion as the divergence of $\mathbf{u}$, i.e., $\nabla \cdot \mathbf{u}$. This measure, when divided by the intersession interval, has units of fractional loss/gain per year and assumes values typically in the range of $\pm 0.01 \mathrm{yr}^{-1}$ (i.e., $\pm 1 \%$ per year). All images are shown in units of percentage change per year.

$\left[{ }^{18} \mathrm{~F}\right] F D G$-PET maps of glucose metabolism. Regional reduction in the cerebral metabolic rate of glucose (CMRgl) in $\mathrm{AD}$ relative to agematched nondemented individuals is a highly reproducible finding (for review, see Herholz, 1995; Perani and Cappa, 2001). The present study obtained a stable map of CMRgl reductions associated with AD based on data published previously in a large-scale multi-center FDG study by Herholz et al. (2002). The data were collected in seven separate centers and included 395 individuals ( 169 males and 226 females) with probable $\mathrm{AD}$ [mean age, 69 years; mean Mini Mental State Examination (MMSE) (Folstein et al., 1975) score, 19]. A map was produced by directly regressing CMRgl against MMSE score in the AD patients (Folstein et al., 1975, their Fig. 2). Here the slope of the regression line was used as a map of the strength of the association between CMRgl and MMSE. This image represents regions in which $\mathrm{CMRgl}$ decreases in proportion to cognitive impairment in AD. K. Herholz (University of Cologne, Koln, Germany) generously provided the data. The map was made to conform to the present atlas by application of a 12-parameter affine transform connecting the Montreal Neurological Institute template to our atlas representative target image.

fMRI maps of retrieval success. Functional studies have revealed a number of correlates of memory at both encoding and retrieval. One prominent effect is the "retrieval success" (also sometimes referred to as the old/new effect) that reflects regions more active when participants cor- rectly identify items previously presented (hits) compared with rejecting new items [correct rejections (CRs)] (Wagner et al., 2005). Retrieval success effects have consistently included cortical responses in medial and lateral parietal regions. One hypothesis is that the retrieval success effect reflects cortical regions interacting with the medial temporal lobe during memory retrieval (Buckner and Wheeler, 2001; Shannon and Buckner, 2004). Here a stable map of regions showing retrieval success effects was constructed by combining data from five previous studies of young adults (ages were $18-35$ years) incorporating eight separate retrieval conditions (275 fMRI runs from 105 individuals). Data included eight recognition conditions from Konishi et al. (2000), Wheeler and Buckner [2004 (remember and know trials only)], and Shannon and Buckner [2004 (all three experiments with deep study trials only from experiment 3 )]. As a first step, the maps from each condition were independently constructed, and a threshold of $p<0.001$ was applied to identify those voxels showing hits $>$ correct rejections. A second image was then constructed displaying convergence across conditions, scaling the image by whether $100 \%$ (eight of eight), $87.5 \%$ (seven of eight), or $75 \%$ (six of eight) of the conditions were significant. This image thus represents a conservative estimate of regions showing retrieval success effects based on eventrelated $\mathrm{fMRI}$ in healthy, young adults.

\section{Results}

\section{$\left[{ }^{15} \mathrm{O}\right] \mathrm{H}_{2} \mathrm{O}$-PET maps of default mode activity}

Figure 1 shows the common, default mode activity in young adults. Two patterns are notable. First, a distributed network of regions is more active in the default state. Second, the activated default network prominently includes the precuneus (the portion of the parietal lobe caudal to the paracentral lobule) extending into posterior cingulate and retrosplenial cortex, as well as lateral posterior parietal regions. Frontal regions along the midline are also prominently active. This data pattern is consistent with analyses of default activity across numerous studies (Mazoyer et al., 2001; McKiernan et al., 2003). Default mode activity is also observed in the medial temporal lobe consistent with recent analyses of Greicius et al. (2004).

\section{$\left[{ }^{11}\right.$ C]PIB-PET maps of amyloid deposition}

Because of the novelty of these methods, analyses began by first establishing the reliability of the PIB amyloid binding pattern. For this analysis, the sample of older adults with $\mathrm{AD}$ was randomly divided into two matched groups (each $n=5$ ). Data from each of the groups (referred to as SPLIT ONE and SPLIT TWO) was averaged and plotted independently. Results are shown as supplemental Figure 1 (available at www.jneurosci. org as supplemental material). An extremely high level of stability of the PIB binding pattern was observed from one group to the next.

Having established reliability, maps of PIB binding were constructed for the main data sets. Inspection of normalized PIB imaging from individuals showed two types of results. PIB "positive" images had extensive increased PIB uptake. PIB "negative" images showed essentially no PIB uptake in cortical regions that exceeded brainstem (or any white matter) uptake. This division, which is not intended as a surrogate for clinical diagnosis, was used in constructing group maps. Three maps were produced that are plotted in Figure 2. Two individual nondemented participants demonstrated $\mathrm{PIB}^{+}$responses and were plotted separately $\left(\mathrm{NONDEMENTED} \mathrm{PIB}^{+}\right.$) from the remaining six nondemented participants who were $\mathrm{PIB}^{-}$(NONDEMENTED PIB ${ }^{-}$). We chose to present the data using this post hoc division of nondemented older adults to illustrate the low level of cortical PIB binding in most nondemented older adults and also the topography of PIB binding, when present, in nondemented individuals. 
Variation in individual uptake of PIB, which may provide an important marker for disease pathology and progression (Klunk et al., 2004), is not analyzed here but will appear in future reports. The main focus in the present report is on the topographic pattern of PIB binding in the averaged group maps. All of the individuals with $\mathrm{AD}$ were averaged together, regardless of the magnitude of PIB response (DEMENTED).

In the individuals with $\mathrm{AD}, \mathrm{PIB}$ binding was widely distributed across the cortex, prominently including frontal regions along the midline extending laterally, as well as medial and lateral posterior parietal regions. Posterior cortical deposition included the precuneus extending into posterior cingulate and retrosplenial cortex. A similar pattern of PIB binding was also present in the two nondemented individuals who were $\mathrm{PIB}^{+}$, suggesting the possibility that PIB binding may be present before the clinical expression of $\mathrm{AD}$ as dementia in some participants. PIB was relatively absent in all cortical regions, including those affected in $\mathrm{AD}$, in the nondemented PIB ${ }^{-}$group. Nonspecific binding in white matter was observed, consistent with previous reports (Klunk et al., 2004), in all groups including the nondemented participants who were $\mathrm{PIB}^{-}$.

\section{MRI maps of longitudinal}

structural atrophy

Atrophy maps are presented in Figure 3. Images use a threshold of $0.4 \%$ per year atrophy. In the individuals with $\mathrm{AD}$, marked atrophy was observed in medial temporal regions as well as in a distributed network of cortical regions that prominently included the precuneus, posterior cingulate, retrosplenial cortex, and lateral posterior parietal regions (consistent with Scahill et al., 2002). In contrast, these regions did not show accelerated atrophy in the nondemented older adults.

Atrophy maps that separated participants by dementia severity were further constructed using three groups: CONVERTER, VERY MILD, and MILD. These three groups contained individuals that were nondemented $(n=8)$, very mildly demented $(n=31)$, and mildly demented $(n=9)$ individuals with $\mathrm{AD}$ at the baseline structural imaging session; all were at least CDR 0.5 (very mild dementia) at follow-up. Results indicated a clear acceleration of atrophy rate as dementia severity increased. Of importance, medial temporal and precuneus atrophy was detected at the earliest stages of the disease, even among those individuals with very mild dementia, as well as converters (nondemented individuals who developed very mild dementia). As dementia severity increased, atrophy rates accelerated and expanded to widespread cortical regions, including frontal cortex.

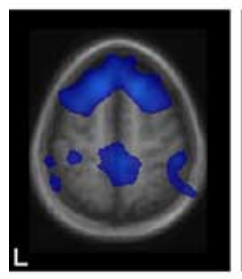

$Z=54$ the midline. $\left[{ }^{15} \mathrm{O}\right] \mathrm{H}_{2} \mathrm{O}$ PET DEFAULT NETWORK ACTIVITY IN YOUNG ADULTS

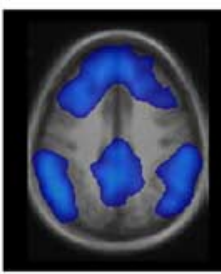

$Z=38$

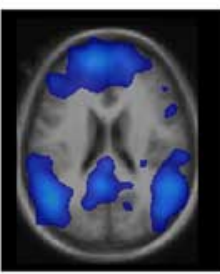

$Z=22$

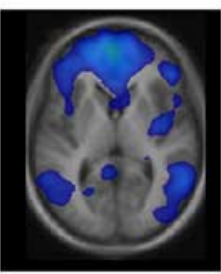

$Z=6$

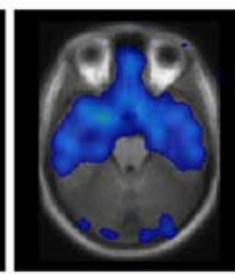

$Z=-22$
Figure 1. Default mode activity in young adults measured by $\left[{ }^{15} \mathrm{O}\right] \mathrm{H}_{2} \mathrm{O} \mathrm{PET}$. Transverse (horizontal) sections through the brain show activity during default states in young adults from a meta-analysis of nine studies (data from Shulman et al., 1997b). The left hemisphere is displayed on the left. Section labels (at bottom) correspond to the approximate transverse level from the Talairach and Tournoux (1988) atlas. Scale is in percentage of PET counts. Notable default mode activity is apparent in medial and lateral posterior parietal regions, extending into precuneus, posterior cingulate, and retrosplenial cortex, as well as in frontal cortex along

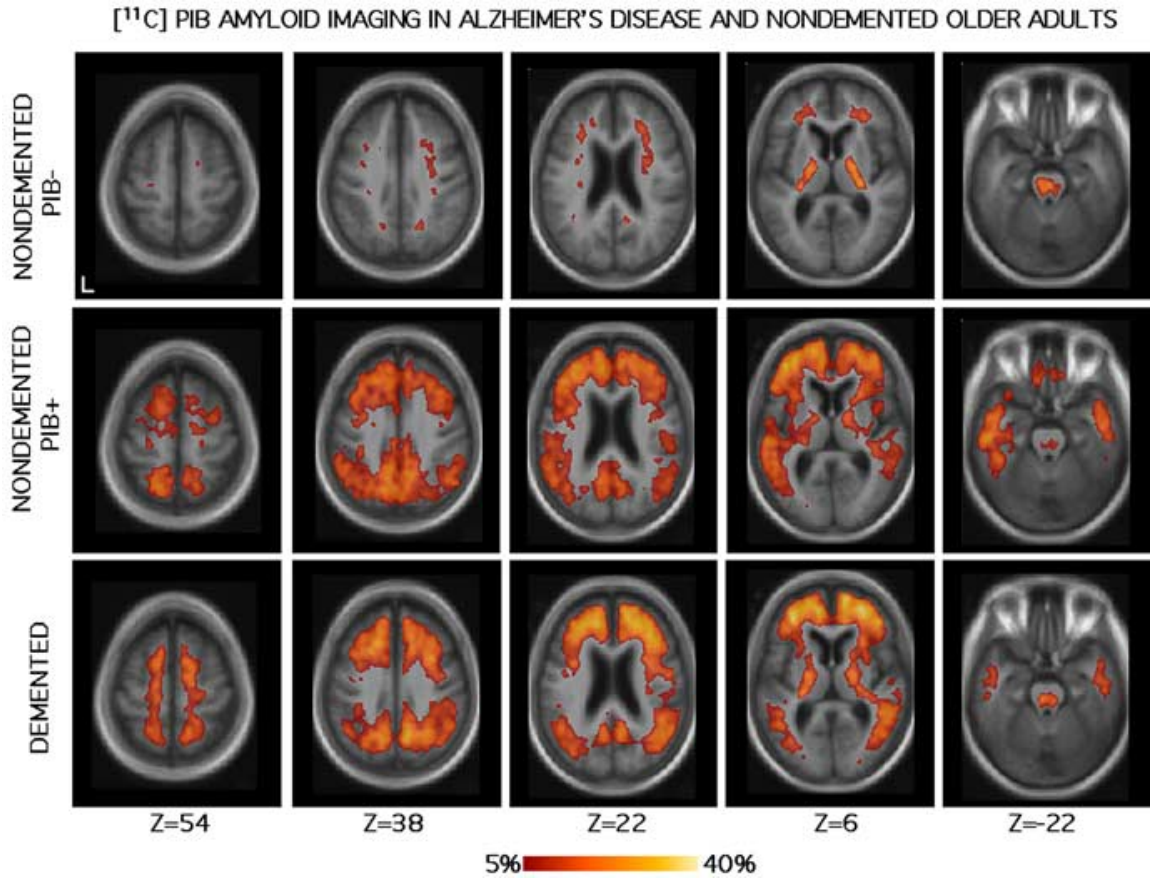

Figure 2. Amyloid deposition in older adults measured by $\left[{ }^{11} \mathrm{C}\right] \mathrm{PIB}$. The format is similar to Figure 1 . The scale is a percentage of uptake above brainstem activity (see Materials and Methods). The top image shows nondemented older adults $(n=6)$ who have minimal amyloid deposition (PIB ${ }^{-}$). There is nonspecific binding of $\left[{ }^{11} \mathrm{C}\right] \mathrm{PIB}$ in white matter. The middle image shows nondemented older adults $(n=2)$ who have significant amyloid deposition ( $\left.\mathrm{PIB}^{+}\right)$, perhaps indicating preclinical AD. The bottom image shows demented older adults $(n=10)$. Notable amyloid deposition is apparent in medial and lateral posterior parietal regions, extending into precuneus, posterior cingulate, and retrosplenial cortex, as well as in frontal cortex along the midline. Medial temporal amyloid deposition is minimal. This pattern of amyloid deposition in AD is reliable across separate participants groups (supplemental Fig. 1, available at www.jneurosci.org as supplemental material).

\section{$\left[{ }^{18}\right.$ F]FDG-PET maps of glucose metabolism}

Figure 4 shows regions of decreasing glucose metabolism in relation to dementia severity (as measured by the MMSE). The image threshold is set at 50, which reflects the strength of the regression of MMSE and CMRgl (see Materials and Methods). Prominent metabolism reductions are noted in precuneus extending into posterior cingulate and retrosplenial cortex, as well as lateral posterior parietal regions. At this threshold, frontal regions along the midline are not prominent. Reductions in frontal regions are evident in displays at lower threshold values (supplemental Fig. 3, available at www. 
STRUCTURAL MRI ATROPHY IN ALZHEIMER'S DISEASE AND NONDEMENTED OLDER ADULTS
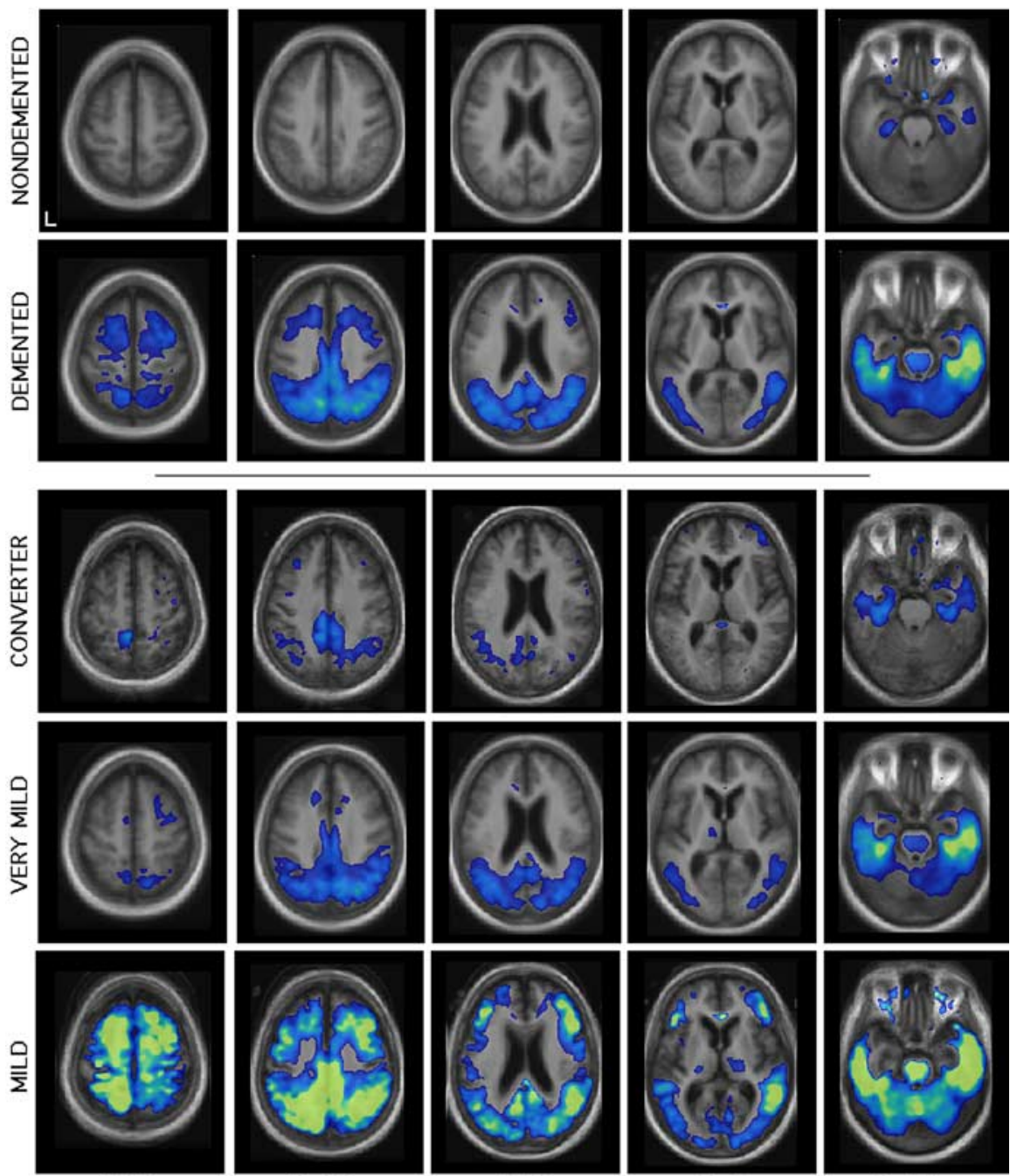

$Z=38$

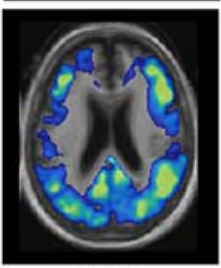

$\mathrm{Z}=22$

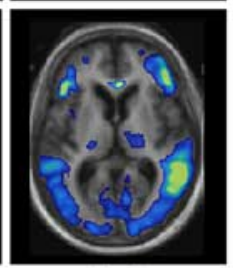

$\mathrm{Z}=6$

\section{$0.4 \%=1.0 \%$}

Figure 3. Longitudinal atrophy in older adults measured by structural MRI. The format is similar to Figure 1. The scale is atrophy rate, per year. Top, The top two rows show nondemented $(n=44)$ and demented $(n=40)$ individuals. The demented group includes all participants classified as CDR 0.5 or 1 coincident with the first imaging session. Atrophy is clearly apparent in the medial temporal lobe. In the cortex, posterior cortical regions, extending into precuneus, posterior cingulate, and retrosplenial cortex, show prominent atrophy. Bottom, The bottom three rows show atrophy sorted by disease severity. Converters $(n=8)$ were nondemented (CDR 0$)$ at initial imaging and progressed to very mild dementia (CDR 0.5$)$ during the study. Very mildly demented individuals $(n=31)$ were all enrolled at CDR 0.5. Mildly demented individuals $(n=9)$ were enrolled at CDR 1 . Although the topography of the atrophy pattern is preserved across levels of dementia severity, clear acceleration of atrophy rate is apparent as disease severity increases. In the converter group, the earliest indications of atrophy are observed in the medial temporal lobe and posterior cortical regions.

jneurosci.org as supplemental material). This general pattern of metabolism reduction in $\mathrm{AD}$ is highly similar to that reported in multiple studies in the literature (see atlas-based analyses of Ishii et al., 2001; Reiman et al., 1996).

\section{fMRI maps of retrieval success}

Retrieval success is defined here as more activity to hits (old items correctly identified as old) compared with CRs (new items identified as new). Regions that consistently revealed retrieval success effects in young adults are shown in Figure 5. Prominent retrieval success effects were noted in precuneus extending into posterior cingulate and retrosplenial cortex and also lateral parietal cortex (left $>$ right). These effects, which include auditory and visual

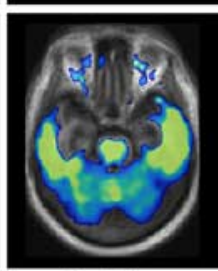

$Z=-22$ conditions, verbal and nonverbal conditions, and those requiring different response modes, were present in $100 \%$ of the studies surveyed. Although not illustrated, the retrieval success effect results from a combination of decreased response below baseline for CR trials and an increase above baseline to hits, with some regional variation, as described previously (Henson et al., 1999; Konishi et al., 2000; Donaldson et al., 2001; Wheeler and Buckner, 2004).

\section{Convergence and divergence across imaging methods}

A central feature of the present approach is that the separate maps can be directly compared because of their common anatomic registration. Across the methods, there is notable convergence in posterior regions near precuneus extending into the posterior cingulate and retrosplenial cortex and also in lateral posterior parietal cortex (Fig. 6). There is less convergence in other regions including frontal cortex that show marked default activity and PIBmeasured amyloid deposition but less (not absent) atrophy and metabolism reduction (Fig. 6) (supplemental Fig. 3, available at www.jneurosci.org as supplemental material). The most notable difference across methods was the observation of robust atrophy within the medial temporal lobes in regions that did not show significant amyloid deposition or metabolism reduction. Table 4 summarizes convergence and divergence across the five methods.

\section{Discussion}

Amyloid deposition occurs in regions active during young adult default states The present analyses revealed a remarkable and surprising correlation in cortical regions between default activity in young adults and the pattern of amyloid deposition in elderly individuals with AD. This correlation suggests that young adult activity and metabolism patterns may be conducive to amyloid deposition in $\mathrm{AD}$, insofar as cortical regions are concerned. Studies of cognitive ability (Snowdon et al., 1996) and genetic polymorphisms (Reiman et al., 2004) suggest that variation in young adults is predictive of AD. Reiman et al. (2004) recently noted metabolism differences in young-adult carriers of the high (AD) risk $\epsilon 4$ allele, prominently including posterior cingulate. The present results suggest an unexpected possible mechanism for functional differences that lead to, but precede, AD pathology.

Default mode activity in young adults and its associated levels of metabolism (Gusnard and Raichle, 2001) may provide regional conditions conducive to amyloid deposition (Fig. 7). Within this possibility, variation in $\mathrm{AD}$ risk may, in part, be attributable to differences in default activity and associated metab- 
olism patterns across individuals. Vascular factors may also be important.

$\mathrm{A} \beta$ production and amyloid precursor protein regulation have been shown to be activity dependent, providing some plausibility for a biological mechanism (Nitsch et al., 1993; Kamenetz et al., 2003). It is possible that already identified factors are mediated through their lifelong effects on metabolism. For example, a recent study of chromosome 12 noted association with the glyceraldehyde-3-phosphate dehydrogenase (GAPDH) gene (Li et al., 2004). GAPDH has multiple biological roles, including those associated with apoptosis and energy metabolism (glycolysis). Whereas the original report emphasized the role of GAPDH in apoptosis, the present results encourage exploration of whether the influence might be through a metabolism-mediated mechanism.

Amyloid deposition correlates with atrophy and metabolism reduction in posterior cortical regions

Atrophy was present in the precuneus at the earliest stages of conversion to $\mathrm{AD}$ and expanded to include more diffuse medial and lateral posterior parietal regions in very mild stages (Scahill et al., 2002; Thompson et al., 2003). Mild AD was associated with widespread accelerated atrophy that included frontal regions. The topography of atrophy overlapped the cortical distribution of amyloid deposition, with few exceptions, in mild AD. Thus, within cortex, in vivo measures of amyloid deposition based on PIB are associated with atrophy in AD. Showing convergence with the cortical atrophy results, glucose metabolism differences in $\mathrm{AD}$ also showed a pattern that markedly overlapped that of cortical atrophy (compare Figs. 2, 4; see Fig. 6) (supplemental Fig. 3, available at www.jneurosci.org as supplemental material). In contrast to the cortical patterns noted above, less amyloid deposition is detected in the hippocampal formation in which marked atrophy occurs early in the progression of $\mathrm{AD}$, consistent with a growing number of studies in the literature (for review, see Jack and Petersen, 2000). We will return to this mismatch later.

Across the extent of amyloid deposition, the precuneus, posterior cingulate, and retrosplenial cortex were particularly vulnerable to atrophy. Other regions, including frontal cortex, were vulnerable at lower levels and later stages but, in relation to posterior regions, were relatively spared. The finding of preferential effects in posterior regions may indicate regional
FDG PET GLUCOSE METABOLISM DISRUPTION IN ALZHEIMER'S DISEASE

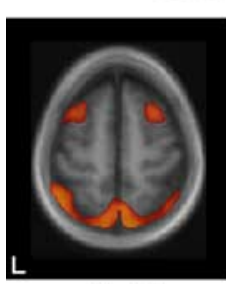

$Z=54$

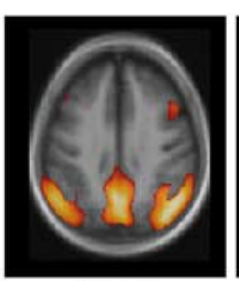

$Z=38$

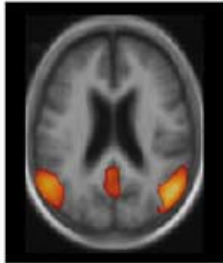

$Z=22$

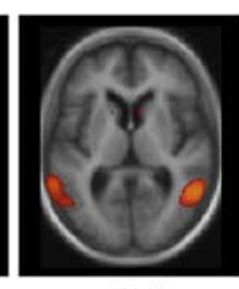

$\mathrm{Z}=6$

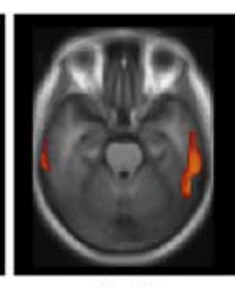

$Z=-22$
Figure 4. Metabolism reduction in Alzheimer's disease measured by FDG-PET. The format is similar to Figure 1. The scale reflects the slope of the regression between CMRgl and dementia severity as measured by the MMSE. All included participants ( $n=395$ ) were demented (data from Herholz et al., 2002). Regions showing metabolism reduction as dementia severity increases include posterior cortical regions near precuneus extending into posterior cingulate and retrosplenial cortex, as well as to lateral temporoparietal regions.

\section{EVENT-RELATED FMRI RETRIEVAL SUCCESS EFFECTS IN YOUNG ADULTS}

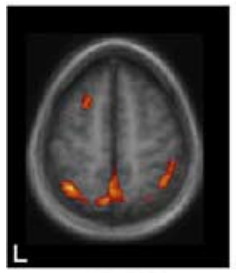

$Z=54$

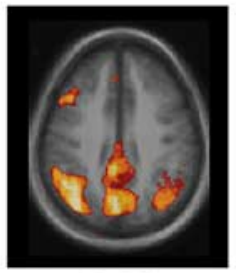

$Z=38$

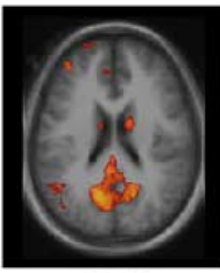

$\mathrm{Z}=22$

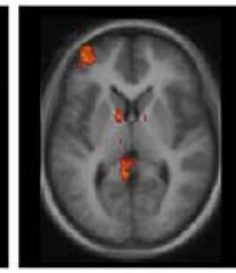

$\mathrm{Z}=6$

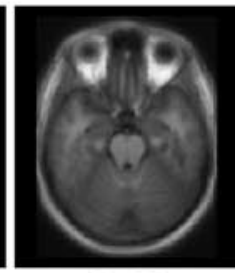

$Z=-22$
Figure 5. Retrieval success effects in young adults measured by event-related fMRI. The format is similar to Figure 1. The scale reflects the number of independent conditions/studies that showed significant differences between hits and correct rejections in a meta-analysis of studies (see Materials and Methods). Regions within precuneus extending into posterior cingulate and retrosplenial cortex, as well as lateral parietal cortex and a frontal region near premotor cortex, all showed significant retrieval success effects in $100 \%$ (8 of 8 ) of the included studies.

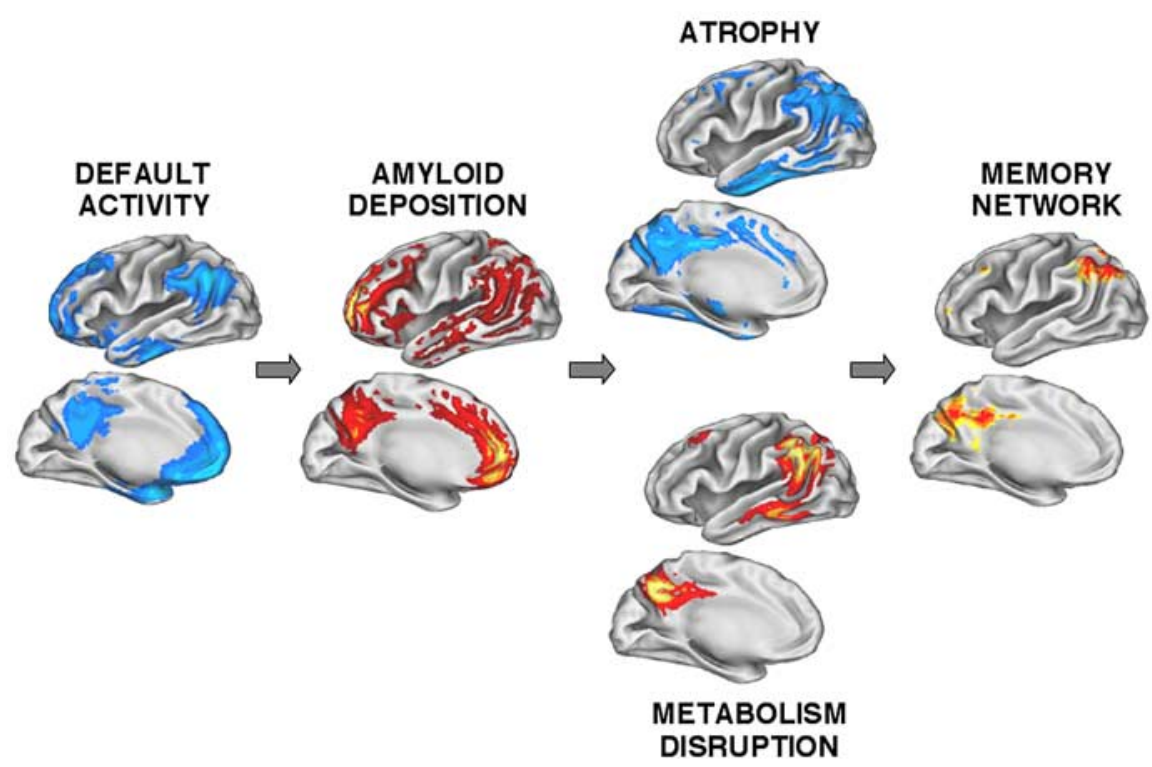

Figure 6. Convergence and hypothetical relationships across molecular, structural, and functional measures. Each image represents the projection of data from Figures 1-5 onto the cortical surface of the left hemisphere (see Results). Three patterns emerge. First, regions showing default activity in young adults are highly similar to those showing amyloid deposition in older adults with $A D$, including both posterior cortical regions and anterior regions. Second, atrophy and metabolism disruption in $A D$ prominently affect the posterior cortical regions also affected by amyloid deposition and less so the anterior regions (supplemental Fig. 3, available at www.jneurosci.org as supplemental material). Third, the regions affected in AD and those active in default states in young adults overlap memory networks showing retrieval success effects during recognition in young adults. 
Table 4. Summary of effects across modalities

\begin{tabular}{lccccc}
\hline Region & Default & Amyloid & Metab & Atrophy & RSE \\
\hline Medial temporal & + & - & - & + & - \\
Prefrontal & + & + & $-/+$ & $-/+$ & - \\
Lateral temporal & + & + & + & + & - \\
Retrosplenial/precuneus & + & + & + & + & + \\
Lateral parietal & + & + & + & + & $+^{a}$
\end{tabular}

$\overline{\text { Default, Presence in PET default network; Amyloid, presence in amyloid imaging measured by PIB; Metab, present as }}$ hypometabolism; Atrophy, presence in longitudinally estimated atrophy; RSE, presence in FMRI measured retrieval success effect; - , minimal or no effect; + , robust effect; $-/+$, minimal effect early in disease progression, robust effect later in progression.

${ }^{a}$ Lateralized (left $>$ right)

Figure 7. A schematic illustration of one possible configuration of lifelong events that lead to AD. Conducive metabolic conditions, associated with default mode activity patterns, may lead to regionally specific amyloid deposition. In turn, atrophy and dementia may then result. This metabolism cascade should be considered a hypothesis.

variation in the vulnerability to amyloid toxicity and also that amyloid burden alone may be insufficient to account for $\mathrm{AD}$ pathophysiology. Regional variation in metabolism (e.g., the level of glycolysis), vascular properties, and susceptibility to molecular vulnerabilities such as excitotoxicity are all plausible candidates for explaining this heterogeneity.

These results prompt the question of whether acquired lesions in the posterior cortical regions highlighted here yield deficits that are consistent with symptoms of AD. Human lesions along the posterior midline can produce memory impairment, a phenomenon termed "retrosplenial amnesia" (Valenstein et al., 1987). Kobayashi and Amaral (2003) noted several cases of retrosplenial damage that were associated with relatively selective and severe memory impairment, including individuals with well circumscribed lesions. In contrast, there is minimal precedent of lateral posterior parietal cortex lesions producing deficits reminiscent of $\mathrm{AD}$. Lesions to lateral posterior parietal cortex produce neglect (Mesulam, 1999) and apraxia (Heilman and Gonzalez Rothi, 1993). Additional studies correlating lesions of parietal regions and memory performance will be informative.

Taken collectively, the present results suggest that posterior cortical regions, in particular those that form a network with the medial temporal lobe and participate in memory function, may be directly and preferentially affected in $\mathrm{AD}$ early in disease progression.

\section{Memory networks are active during the default mode, suggesting a mechanism for why memory is preferentially affected early in AD}

Functional imaging studies suggest that there exists a default activity pattern that is engaged in many unconstrained task situations. Providing initial evidence for this possibility, Shulman et al. (1997b) defined a network of brain regions commonly activated by young adults when imaged in passive (unconstrained) task states relative to a wide range of directed task states (Mazoyer et al., 2001; McKiernan et al., 2003). Raichle and colleagues (Gusnard and Raichle, 2001; Raichle et al., 2001) suggested that this network participates in a default mode or state of human cognition because of its consistent appearance across numerous studies and differences in metabolic profile (Gusnard and Raichle, 2001). The default activity pattern is reproduced here in Figure 1. What remains elusive is identification of the cognitive operations (if any) performed in the default state. Our results suggest that memory processes may be a prominent component of the default mode and, by implication, that involvement of memory networks in default states may contribute to why memory is preferentially vulnerable in $\mathrm{AD}$.

The notion that memory may play a prominent role in default cognitive states has arisen previously based on verbal reports of subjects (Andreasen et al., 1995; Mazoyer et al., 2001). Greicius and colleagues (Greicius et al., 2003, 2004; Greicius and Menon, 2004) came to a similar conclusion on the basis of functional connectivity results in fMRI data: namely, that memory is an important component of the default mode. In their analysis, they correlated resting state activity patterns and identified a network similar to that of the default network of Shulman et al. (1997b), with the additional observation that the network is correlated with MTL activity (Christoff et al., 2004). A final observation is provided by the present results, which show overlap between event-related fMRI correlates of successful memory retrieval and regions active in the default mode.

Activity modulation within memory networks in default cognitive states may provide a serendipitous glimpse at what humans do much of the time: while musing, daydreaming, and planning (Ingvar, 1985). The specific possibility raised by the present data is that memory networks are modulated, in some manner, during default cognitive states and, as a result, through as yet unspecified activity- or metabolism-dependent mechanisms, may cause preferential accumulation of amyloid. Vascular mechanisms may also play a role. This admittedly speculative explanation is only one possibility; it is intriguing in that it suggests an explanation for why memory is impaired early in $\mathrm{AD}$. It is also notable that default network activity is disrupted in AD (Lustig et al., 2003; Greicius et al., 2004).

Memory networks have been described previously as having particular vulnerability in $\mathrm{AD}$ based on their anatomic disruption (Hyman et al., 1990) and molecular properties associated with plasticity (Mesulam, 2000). The present results suggest that part of the explanation may lie in the modulation of memory networks as part of default modes of cognition. Default activity patterns, over many years, may augment a metabolic- or activitydependent cascade that participates in $\mathrm{AD}$ pathology.

\section{Caveats and unresolved issues}

The present study has several limitations. First, different data types were contrasted across separate participant groups. Although some comparisons will obligatorily remain between groups (e.g., those involving contrasts between young adults and older adults with $\mathrm{AD}$ ), within-participant comparisons will be necessary to verify several of the relationships suggested here. A persistent unresolved issue is the discrepancy between the cortical patterns of amyloid deposition in $\mathrm{AD}$, which converge on posterior regions near precuneus, and the consistent finding in $\mathrm{AD}$ of prominent early structural changes in medial temporal regions. This difference has been noted and discussed previously (Klunk et al., 2004). A final limitation is the inherent correlational nature of the study. The interpretations and model presented in Figures 6 and 7 represent plausible accounts of the 
present data. Nonetheless, it is important to note that several observations already in the literature suggest alternatives. For example, using a transgenic mouse model of $\mathrm{AD}$, Redwine et al. (2003) showed that hippocampal volume reductions precede amyloid plaque formation. Thus, our preferred interpretations of the present correlational analyses represent only one possible explanation for the data.

Implied in our discussion are four specific and separate hypotheses that can be summarized as follows: (1) default activity/ metabolism patterns in young adults, in some unspecified manner, lead to or modify amyloid deposition; (2) cortical amyloid deposition associates with accelerated atrophy and metabolism reduction; (3) within cortical regions associated with amyloid deposition, some posterior regions are preferentially vulnerable to disruption, and other anterior regions are relatively less vulnerable; and (4) the prominence of memory impairment as an early symptom of $\mathrm{AD}$ is, in part, attributable to modulation of memory networks in default cognitive states. These possibilities are independent. For example, default activity states may play a role in amyloid deposition even if it is not the case that default states preferentially engage memory processes. Similarly, early atrophy in posterior cortical regions may prove to be a reliable indicator of $\mathrm{AD}$ even if default activity states are ultimately shown to be unrelated to the causal cascade. Future research will be required to determine which, if any, of these four causal hypotheses are correct.

\section{References}

Andreasen NC, O’Leary DS, Cizadlo T, Arndt S, Rezai K, Watkins GL, Ponto LL, Hichwa RD (1995) Remembering the past: two facets of episodic memory explored with positron emission tomography. Am J Psychiatry 152:1576-1585.

Berg L, McKeel Jr DW, Miller JP, Storandt M, Rubin EH, Morris JC, Baty J, Coats M, Norton J, Goate AM, Price JL, Gearing M, Mirra SS, Saunders AM (1998) Clinicopathologic studies in cognitively healthy aging and Alzheimer's disease: relation of histologic markers to dementia severity, age, sex, and apolipoprotein E genotype. Arch Neurol 55:326-335.

Black KJ, Snyder AZ, Koller JM, Gado MH, Perlmutter JS (2001a) Template images for nonhuman primate neuroimaging. I. Baboon. NeuroImage 14:736-743.

Black KJ, Koller JM, Snyder AZ, Perlmutter JS (2001b) Template images for nonhuman primate neuroimaging. II. Macaque. NeuroImage 14:744-748.

Braak H, Braak E (1991) Neuropathological stageing of Alzheimer-related changes. Acta Neuropathol (Berl) 82:239-259.

Braak H, Braak E (1997) Staging of Alzheimer-related cortical destruction. Int Psychogeriatr 9 [Suppl 1]:257-261.

Buckner RL (2004) Memory and executive function in aging and AD: multiple factors that cause decline and reserve factors that compensate. Neuron 44:195-208.

Buckner RL, Wheeler ME (2001) The cognitive neuroscience of remembering. Nat Rev Neurosci 2:624-634.

Buckner RL, Head D, Parker J, Fotenos A, Marcus D, Morris JC, Snyder AZ (2004) A unified approach for morphometric and functional data analysis in young, old, and demented adults using automated atlas-based head size normalization: reliability and validation against manual measurement of total intracranial volume. NeuroImage 23:724-738.

Burton H, Abend NS, MacLeod AM, Sinclair RJ, Snyder AZ, Raichle ME (1999) Tactile attention tasks enhance activation in somatosensory regions of parietal cortex: a positron emission tomography study. Cereb Cortex 9:662-674.

Christensen GE, Rabbitt RD, Miller MI (1996) Deformable templates using large deformation kinematics. IEEE Trans. Image Processing 5:1435-1447.

Christoff K, Ream JM, Gabrieli JDE (2004) Neural basis of spontaneous thought processes. Cortex 40:623-630.

Donaldson DI, Petersen SE, Buckner RL (2001) Dissociating memory re- trieval processes using fMRI: evidence that priming does not support recognition memory. Neuron 31:1047-1059.

Folstein MF, Folstein SE, McHugh PR (1975) “Mini-mental state.” A practical method for grading the cognitive state of patients for the clinician. J Psychiatr Res 12:189-198.

Fotenos AF, Snyder AZ, Girton LE, Morris JC, Buckner RL (2005) Normative estimates of cross-sectional and longitudinal brain volume decline in aging and AD. Neurology 64:1032-1039.

Fox NC, Warrington EK, Rossor MN (1999) Serial magnetic resonance imaging of cerebral atrophy in preclinical Alzheimer's disease. Lancet 353:2125.

Fox NC, Crum WR, Scahill RI, Stevens JM, Janssen JC, Rossor MN (2001) Imaging of onset and progression of Alzheimer's disease with voxelcompression mapping of serial magnetic resonance images. Lancet 358:201-205.

Freeborough PA, Woods RP, Fox NC (1996) Accurate registration of serial 3D MR brain images and its application to visualizing change in neurodegenerative disorders. J Comput Assist Tomogr 20:1012-1022.

Friedland RP, Budinger TF, Ganz E, Yano Y, Mathis CA, Koss B, Ober BA, Huesman RH, Derenzo SE (1983) Regional cerebral metabolic alterations in dementia of the Alzheimer type: positron emission tomography with $\left[{ }^{18} \mathrm{~F}\right]$ fluorodeoxyglucose. J Comput Assist Tomogr 7:590-598.

Gómez-Isla T, Price JL, McKeel DW, Morris JC, Growdon JH, Hyman BT (1996) Profound loss of layer II entorhinal cortex neurons occurs in very mild Alzheimer's disease. J Neurosci 16:4491-4500.

Greicius MD, Menon V (2004) Default-mode activity during a passive sensory task: uncoupled from deactivation but impacting activation. J Cogn Neurosci 16:1484-1492.

Greicius MD, Krasnow B, Reiss AL, Menon V (2003) Functional connectivity in the resting brain: a network analysis of the default mode hypothesis. Proc Natl Acad Sci USA 100:253-258.

Greicius MD, Srivastava G, Reiss AL, Menon V (2004) Default-mode network activity distinguishes Alzheimer's disease from healthy aging: evidence from functional MRI. Proc Natl Acad Sci USA 101:4637-4642.

Gusnard DA, Raichle ME (2001) Searching for a baseline: functional imaging and the resting human brain. Nat Rev Neurosci 2:685-694.

Heilman KM, Gonzalez Rothi LJ (1993) Apraxia. In: Clinical neuropsychology, Ed 3 (Heilman KM, Valenstein E, eds), pp 141-163. New York: Oxford UP.

Henson RN, Rugg MD, Shallice T, Josephs O, Dolan RJ (1999) Recollection and familiarity in recognition memory: an event-related functional magnetic resonance imaging study. J Neurosci 19:3962-3972.

Herholz K (1995) FDG PET and differential diagnosis of dementia. Alzheimer Dis Assoc Disord 9:6-16.

Herholz K, Salmon E, Perani D, Baron, JC, Holthoff V, Frölich L, Schonknecht P, Ito K, Mielke R, Kalbe E, Zundorf G, Delbeuck X, Pelati O, Anchisi D, Fazio F, Kerrouche N, Desgranges B, Eustache F, BeuthienBaumann B, Menzel C, et al. (2002) Discrimination between Alzheimer dementia and controls by automated analysis of multicenter FDG PET. NeuroImage 17:302-316.

Hyman BT, Van Hoesen GW, Damasio AR, Barnes CL (1984) Alzheimer's disease: cell-specific pathology isolates the hippocampal formation. Science 225:1168-1170.

Hyman BT, Van Hoesen GW, Damasio AR (1990) Memory-related neural systems in Alzheimer's disease: an anatomic study. Neurology 40:1721-1730.

Ingvar DH (1985) "Memory of the future": an essay on the temporal organization of conscious awareness. Hum Neurobiol 4:127-136.

Insausti R, Amaral DG, Cowan WM (1987) The entorhinal cortex of the monkey. II. Cortical afferents. J Comp Neurol 264:356-395.

Ishii K, Willoch F, Minoshima S, Drzezga A, Ficaro EP, Cross DJ, Kuhl DE, Schwaiger M (2001) Statistical brain mapping of 18F-FDG PET in Alzheimer's disease: validation of anatomic standardization for atrophied brains. J Nucl Med 42:548-557.

Jack Jr CR, Petersen RC (2000) Structural imaging approaches to Alzheimer's disease. In: Early diagnosis and treatment of Alzheimer's disease (Scinto LFM, Daffner KR, eds), pp 127-148. Totowa, NJ: Human.

Jack Jr CR, Shiung MM, Gunter JL, O'Brien PC, Weigand SD, Knopman DS, Boeve BF, Ivnik RJ, Smith GE, Cha RH, Tangalos EG, Petersen RC, (2004) Comparison of different MRI brain atrophy rate measures with clinical disease progression in AD. Neurology 62:591-600.

Kamenetz F, Tomita T, Hsieh H, Seabrook G, Borchelt D, Iwatsubo T, Sisodia S, Malinow R (2003) APP processing and synaptic function. Neuron 37:925-937. 
Khachaturian ZS (1985) Diagnosis of Alzheimer's disease. Arch Neurol 42:1097-1105.

Killiany RJ, Hyman BT, Gómez-Isla T, Moss MB, Kikinis R, Jolesz F, Tanzi R, Jones K, Albert MS (2002) MRI measures of entorhinal cortex vs hippocampus in preclinical AD. Neurology 58:1188-1196.

Klunk WE, Wang Y, Huang GF, Debnath ML, Holt DP, Mathis CA (2001) Uncharged thioflavin-T derivatives bind to amyloid-beta protein with high affinity and readily enter the brain. Life Sci 69:1471-1484.

Klunk WE, Engler H, Nordberg A, Wang Y, Blomqvist G, Holt DP, Bergström M, Savitcheva I, Huang GF, Estrada S, Ausén B, Debnath ML, Barletta J, Price JC, Sandell J, Lopresti BJ, Wall A, Koivisto P, Antoni G, Mathis CA, Longström B (2004) Imaging brain amyloid in Alzheimer's disease with Pittsburg Compound-B. Ann Neurol 55:306-319.

Kobayashi Y, Amaral DG (2003) Macaque monkey retrosplenial cortex. II. cortical afferents. J Comp Neurol 466:48-79.

Konishi S, Wheeler ME, Donaldson DI, Buckner RL (2000) Neural correlates of episodic retrieval success. NeuroImage 12:276-286.

Kung MP, Hou C, Zhuang ZP, Zhang B, Skovronsky D, Trojanowski JQ, Lee VM, Kung HF (2002) IMPY: an improved thioflavin-T derivative for in vivo labeling of beta-amyloid plaques. Brain Res 956:202-210.

Li Y, Nowotny P, Holmans P, Smemo S, Kauwe JSK, Hinrichs AL, Tacey K, Doil L, van Luchene R, Garcia V, Rowland C, Schrodi S, Leong D, Gogic G, Chan J, Cravchik A, Ross D, Lau K, Kwok S, Chang SY, et al. (2004) Association of late-onset Alzheimer's disease with genetic variation in multiple members of the GAPD gene family. Proc Natl Acad Sci USA 101:15688-15693.

Lustig C, Snyder AZ, Bhakta M, O’Brien KC, McAvoy M, Raichle ME, Morris JC, Buckner RL (2003) Functional deactivations: change with age and dementia of the Alzheimer type. Proc Natl Acad Sci USA 100:14504-14509.

Mathis CA, Bacskai BJ, Kajdasz ST, McLellan ME, Frosch MP, Hyman BT, Holt DP, Wang Y, Huang GF, Debnath ML, Klunk WE (2002) A lipophilic thioflavin-T derivative for positron emission tomography (PET) imaging of amyloid in brain. Bioorg Med Chem Lett 12:295-298.

Mathis CA, Wang Y, Holt DP, Huang GF, Debnath ML, Klunk WE (2003) Synthesis and evaluation of ${ }^{11} \mathrm{C}$-labeled 6-substituted 2-arylbenzothiazoles as amyloid imaging agents. J Med Chem 46:2740-2754.

Mazoyer B, Zago L, Mellet E, Bricogne S, Etard O, Houdé O, Crivello F, Joliot M, Petit L, Tzourio-Mazoyer N (2001) Cortical networks for working memory and executive functions sustain the conscious resting state in man. Brain Res Bull 54:287-298.

McKiernan KA, Kaufman JN, Kucera-Thompson J, Binder JR (2003) A parametric manipulation of factors affecting task-induced deactivation in functional neuroimaging. J Cogn Neurosci 15:394-408.

Meguro K, Blaizot X, Kondoh Y, Le Mestric C, Baron JC, Chavoix C (1999) Neocortical and hippocampal glucose hypometabolism following neurotoxic lesions of the entorhinal and perirhinal cortices in the non-human primate as shown by PET. Implications for Alzheimer's disease. Brain 122:1519-1531.

Mesulam MM (1999) Spatial attention and neglect: parietal, frontal, and cingulated contributions to the mental representation and attentional targeting of salient extrapersonal events. Philos Trans R Soc Lond B Biol Sci 354:1325-1346.

Mesulam MM (2000) A plasticity-based theory of the pathogenesis of Alzheimer's disease. Ann NY Acad Sci 924:42-52.

Miller MI (2004) Computational anatomy: shape, growth, and atrophy comparison via diffeomorphisms. NeuroImage 23:19-33.

Mirra SS, Heyman A, McKeel D, Sumi SM, Crain BJ, Brownlee LM, Vogel FS, Hughes JP, van Belle G, Berg L (1991) The consortium to establish a registry for Alzheimer's disease (CERAD). II. Standardization of the neuropathological assessment of Alzheimer's disease. Neurology 41:479-486.

Morris JC (1993) The Clinical Dementia Rating (CDR): current version and scoring rules. Neurology 43:2412-2414.

Morris JC, Storandt M, Miller JP, McKeel DW, Price JL, Rubin EH, Berg L (2001) Mild cognitive impairment represents early-stage Alzheimer disease. Arch Neurol 58:397-405.

Morris R, Petrides M, Pandya DN (1999) Architecture and connections of retrosplenial area 30 in the rhesus monkey (Macaca mulatta). Eur J Neurosci 11:2506-2518.

National Institute on Aging (1997) Consensus recommendations for the postmortem diagnosis of Alzheimer's disease. The National Institute on
Aging, and Reagan Institute Working Group on Diagnostic Criteria for the Neuropathological Assessment of Alzheimer's Disease. Neurobiol Aging 18:S1-S2.

Nitsch RM, Farber SA, Growdon JH, Wurtman RJ (1993) Release of amyloid $\beta$-protein precursor derivatives by electrical depolarization of rat hippocampal slices. Proc Natl Acad Sci USA 90:5191-5193.

Perani D, Cappa SF (2001) Brain imaging in normal aging and dementia. In: Handbook of neuropsychology, Vol 6, Aging and dementia (Boller F, Cappa S, eds), pp 429-452. Amsterdam: Elsevier.

Pluim JP, Maintz JB, Viergever MA (2000) Image registration by maximization of combined mutual information and gradient information. IEEE Trans Med Imaging 19:809-814.

Price JL, Davis PB, Morris JC, White DL (1991) The distribution of tangles, plaques, and related immunohistochemical markers in healthy aging and Alzheimer's disease. Neurobiol Aging 12:295-312.

Raichle ME, MacLeod AM, Snyder AZ, Powers WJ, Gusnard DA, Shulman GL (2001) A default mode of brain function. Proc Natl Acad Sci USA 98:676-682.

Redwine JM, Kosofsky B, Jacobs RE, Games D, Reilly JF, Morrison JH, Young WG, Bloom FE (2003) Dentate gyrus volume is reduced before onset of plaque formation in PDAPP mice: a magnetic resonance microscopy and sterologic analysis. Proc Natl Acad Sci USA 100:1381-1386.

Reiman EM, Caselli RJ, Yun LS, Chen K, Bandy D, Minoshima S, Thibodeau SN, Osborne D (1996) Preclinical evidence of Alzheimer's disease in persons homozygous for epsilon 4 allele for apolipoprotein E. N Engl J Med 334:752-758.

Reiman EM, Chen K, Alexander GE, Caselli RJ, Bandy D, Osborne D, Saunders AM, Hardy J (2004) Functional brain abnormalities in young adults at genetic risk for late-onset Alzheimer's dementia. Proc Natl Acad Sci USA 101:284-289.

Scahill RI, Schott JM, Stevens JM, Rossor MN, Fox NC (2002) Mapping the evolution of regional atrophy in Alzheimer's disease: unbiased analysis of fluid-registered serial MRI. Proc Natl Acad Sci USA 99:4703-4707.

Shannon BJ, Buckner RL (2004) Functional-anatomic correlates of memory retrieval that suggest nontraditional processing roles for multiple distinct regions within posterior parietal cortex. J Neurosci 24:10084-10092.

Shoghi-Jadid K, Small GW, Agdeppa ED, Kepe V, Ercoli LM, Siddarth P, Read S, Satyamurthy N, Petric A, Huang SC, Barrio JR (2002) Localization of neurofibrillary tangles and beta-amyloid plaques in the brains of living patients with Alzheimer disease. Am J Geriatr Psychiatry 10:24-35.

Shulman GL, Corbetta M, Buckner RL, Fiez JA, Miezin FM, Raichle ME, Petersen SE (1997a) Common blood flow changes across visual tasks: I. Increases in subcortical structures and cerebellum but not in nonvisual cortex. J Cogn Neurosci 9:624-647.

Shulman GL, Fiez JA, Corbetta M, Buckner RL, Miezin FM, Raichle ME, Petersen SE (1997b) Common blood flow changes across visual tasks: II. Decreases in cerebral cortex. J Cogn Neurosci 9:648-663.

Snowdon DA, Kemper SJ, Mortimer JA, Greiner LH, Wekstein DR, Markesbery WR (1996) Linguistic ability in early life and cognitive function and Alzheimer's disease in late life. Findings from the Nun Study. J Am Med Assoc 275:528-532.

Suzuki WA, Amaral DG (1994) Perirhinal and parahippocampal cortices of the macaque monkey: cortical afferents. J Comp Neurol 350:497-533.

Talairach J, Tournoux P (1988) Co-planar stereotaxic atlas of the human brain. Stuttgart, Germany: Thieme Medical Publishers.

Thompson PM, Hayashi KM, de Zubicaray G, Janke AL, Rose SE, Semple J, Herman D, Hong MS, Dittmer SS, Doddrell DM, Toga AW (2003) Dynamics of gray matter loss in Alzheimer's disease. J Neurosci 23:994-1005

Valenstein E, Bowers D, Verfaellie M, Heilman KM, Day A, Watson RT (1987) Retrosplenial amnesia. Brain 110:1631-1646.

Van Essen DC, Drury HA, Dickson J, Harwell J, Hanlon D, Anderson CH (2001) An integrated software suite for surface-based analyses of cerebral cortex. J Am Med Inform Assoc 8:443-459.

Vogt BA, Finch DM, Olson CR (1992) Functional heterogeneity in cingulate cortex: the anterior executive and posterior evaluative regions. Cereb Cortex 2:435-443.

Wagner AD, Shannon BJ, Kahn I, Buckner RL (2005) Parietal lobe contributions to episodic memory retrieval. Trends Cogn Sci, in press.

Wheeler ME, Buckner RL (2004) Functional-anatomic correlates of remembering and knowing. NeuroImage 21:1337-1349. 